\title{
Surrogate Antibodies That Specifically Bind and Neutralize CCL17 But Not CCL22
}

\author{
Sandra Santulli-Marotto, Jamie Fisher, ${ }^{1}$ Theodore Petley, ${ }^{1}$ Ken Boakye, Tadas Panavas, \\ Jennifer Luongo,' Karl Kavalkovich,' Michael Rycyzyn,' Bingyuan Wu, Lester Gutshall, \\ Ana Coelho, ${ }^{2}$ Cory M. Hogaboam, ${ }^{2}$ and Mary Ryan ${ }^{1}$
}

The chemokines CCL17 (TARC) and CCL22 (MDC) function through the same receptor, CCR4, but have been proposed to differentially affect the immune response. To better understand the role of the individual ligands, a panel of rat anti-mouse CCL17 surrogate antibodies was generated that can be used to differentiate CCL17 and CCL22 function in vitro and in vivo. We have successfully identified a panel of neutralizing antibodies by screening hybridomas for the ability to inhibit CCL17-mediated calcium mobilization. Chemotaxis in response to CCL17 is also inhibited, providing further evidence that the antibodies in this panel are antagonistic. Using a recombinant cell line expressing human CCR4, we show that the antibodies block $\beta$-arrestin recruitment as evidence that the antibodies are specifically blocking CCL17 signaling through CCR4. The antibodies within this panel inhibit calcium mobilization with varying potency in the calcium flux assay, having apparent $\mathrm{IC}_{50}$ ranging from approximately 1 to $>400 \mathrm{ng} / \mathrm{mL}$. Although both CCL17 and CCL22 function through CCR4, only a single antibody was identified as having detectable binding to CCL22. This panel of CCL17-specific antibodies provides tools that can be used to differentiate CCL17 and CCL22 function through CCR4 interaction in vitro and in vivo.

\section{Introduction}

$\mathbf{T}$ HE ONLY KNOWN LIGANDS for the chemokine receptor CCR4 are CCL17 (TARC) and CCL22 (MDC); binding of each elicits distinct consequences. ${ }^{(1,2)}$ CCL22 binds CCR4 with a higher affinity than does CCL17, which may correlate with the differences in CCR4 ${ }^{+}$cell responses to the two chemokines. ${ }^{(1,3)}$ In vitro data have demonstrated that CCL22 has a higher capacity to hold CCR4-expressing cells in place whereas CCL17 has a tendency to permit movement of cells along a gradient, suggesting that these two chemokines have the potential to differentially establish chemotactic gradients. ${ }^{(4)}$ Even interaction with CCR4 reveals differences between the two chemokines in that CCL22 binding readily induces receptor internalization whereas CCL17 interaction with CCR4 mediates internalization poorly. ${ }^{(5,6)}$

At the organismal level, CCL22 has been shown to be instrumental in promoting innate immunity in the response to ceacal ligation and puncture (CLP) in the murine model of experimental sepsis, whereas CCL17 seems to interfere with innate immunity, actually promoting hepatic damage in conditions of systemic LPS. ${ }^{(7,8)}$ CCL22 and CCL17 also have opposing effects on Treg homeostasis in that CCL22 favors Treg recruitment whereas CCL17 has been reported to favor more pro-inflammatory conditions, converting the Treg phenotype to an inflammatory mediator. ${ }^{(9,10)}$ Studies in the CCL17-EGFP mice in which the enhanced green flourescent protein (EGF) coding region was used to disrupt CCL17 expression implicate CCL17 as a major factor in initiating the inflammatory response, establishing a role for CCL17 in contact hypersensitivity. ${ }^{(9,11)}$ CCR4 knockout mice have also been used as a means to inhibit function of CCL17 and CCL22 but data from studies in these mice is incongruent. ${ }^{(12,13)}$ Treatment with a CCR4 antagonist has met with some success in mouse models; however, platelets also express CCR4, which could introduce confounding variables to these studies. ${ }^{(14,15)}$ The ability to target the individual ligands in vivo using neutralizing antibodies provides the opportunity to better understand how each of these molecules contributes to the immune response.

Current data from in vivo CCL17 blocking studies reported in the literature have been generated using commercially available polyclonal antibodies or rat monoclonal anti-CCL17 antibody in mouse models of disease. Neutralizing CCL17 by administration of polyclonal antibody in the murine Aspergillus fumigatus model of asthma conferred enhanced survival compared to mice receiving control antibody. ${ }^{(8)}$ These results strongly suggest that the polyclonal antibody is neutralizing CCL17 function; however, polyclonal antibodies often are promiscuous, making it difficult to be certain that the effects are exclusively the result of CCL17 neutralization. In order to

\footnotetext{
${ }^{1}$ Janssen Research \& Development, Radnor, Pennsylvania.

${ }^{2}$ Department of Pathology, University of Michigan, Ann Arbor, Michigan.
} 
further explore the role of CCL17 in vivo, we generated monoclonal surrogate antibodies and expressed them as chimeric molecules having rat $\mathrm{V}_{\mathrm{L}}$ and $\mathrm{V}_{\mathrm{H}}$ fused with mouse IgG1 Fc. The monoclonal antibodies that have been generated effectively inhibit CCL17 function in vitro by blocking CCL17mediated effects on calcium mobilization, chemotaxis, and $\beta$-arrestin recruitment through CCR4 interaction.

\section{Materials and Methods}

\section{Expression of muCCL17 in Escherichia coli BL21 (DE3)}

E. coli were transformed with the Novagen $\mathrm{pET} 24 \mathrm{~d}$ vector (EMD Millipore, Billerica, MA) expressing full-length mouse CCL17 (A1 to P70) or expressing full-length human CCL17 (A2 toS71); the human protein was expressed with a SUMO tag at the N-terminus. Cells were then cultured in 2-YT medium containing $10 \mu \mathrm{g} / \mathrm{mL}$ kanamycin. Protein expression was induced overnight at $37^{\circ} \mathrm{C}$ with shaking at $250 \mathrm{rpm}$, using IPTG at a final concentration of $1 \mathrm{mM}$. The induced culture was harvested by centrifugation at $4^{\circ} \mathrm{C}, 5000 \mathrm{rpm}$ for $15 \mathrm{~min}$.

Isolation of inclusion bodies. The cell pellet was resuspended in disruption buffer $(20 \mathrm{mM}$ Tris [pH 8.0], $5 \mathrm{mM}$ EDTA) then disrupted using a microfluidizer. The inclusion bodies were collected by centrifugation at $5000 \mathrm{rpm}$ for $20 \mathrm{~min}$, then washed with $20 \mathrm{mM}$ Tris, $5 \mathrm{mM}$ EDTA, and $1 \%$ Triton X-100.

Solubilization of inclusion bodies. Inclusion bodies were solubilized using $8 \mathrm{M}$ urea, $5 \mathrm{mM}$ EDTA, $20 \mathrm{mM}$ Tris $\mathrm{HCl}(\mathrm{pH}$ 7.0 ), and $10 \mathrm{mM}$ DTT incubated at room temperature with constant for $3 \mathrm{~h}$. The solubilized inclusion bodies were clarified by centrifugation at $4^{\circ} \mathrm{C}, 18000 \mathrm{~g}$ for $10 \mathrm{~min}$ and then loaded onto an SPFF XK26/15 column (GE Healthcare Bio-Sciences, Piscataway, NJ) at a flow rate of $1 \mathrm{~mL} / \mathrm{min}$. The column was then washed with Buffer A $(10 \mathrm{mM}$ potassium phosphate $[\mathrm{pH}$ 6.8], $8 \mathrm{M}$ urea) until a flat baseline was achieved. For the elution of the protein, a gradient of $0-100 \% \mathrm{~B}$ (Buffer A plus $1 \mathrm{M} \mathrm{NaCl}$ ) over $6 \mathrm{CV}$ was applied at a flow rate of $8 \mathrm{~mL} / \mathrm{min}$.

Refolding. Refolding was initiated by diluting pooled fractions with refolding buffer at a final concentration of $0.1 \mathrm{M}$ $\mathrm{NaHCO}_{3}, 1.5 \mathrm{M}$ guanidine $\mathrm{HCl}, 3 \mathrm{mM}$ cysteine, and $0.3 \mathrm{mM}$ cystine. Refolding was allowed to proceed at room temperature for $48 \mathrm{~h}$ with gentle stirring followed by incubation in cold room for $66 \mathrm{~h}$.

\section{Hybridoma generation}

Rats (CD1) were immunized with purified recombinant mouse CCL17. Following final boost, splenocytes from one rat were harvested and prepared for fusion.
Lymphocytes were fused at a 1:1 ratio with FO murine myeloma cells according to the method of de St. Groth. ${ }^{(16)}$ The cells were resuspended in HAT medium, then plated in 96well flat-bottom plates. The plates were incubated in a humidified $37^{\circ} \mathrm{C}$ at $6 \% \mathrm{CO}_{2}$ for 7 to 10 days.

Hybridoma culture supernatants were aspirated and replaced with fresh media 7 days after fusion, then screened for antibody production by ELISA on day 10. To screen, Nunc ELISA plates (cat\#446612; ThermoFisher Scientific, Waltham, MA) were coated with Goat anti-Rat IgG ( $\mathrm{Fc})$ $\mathrm{F}(\mathrm{ab})_{2}{ }_{2}$ (Jackson Immunoresearch, West Grove, PA) at $4 \mu \mathrm{g} /$ $\mathrm{mL}$ in coating buffer $(0.1 \mathrm{M}$ BupH Carbonate-bicarbonate Buffer; ThermoFisher Scientific). Following overnight incubation, wells were blocked using $0.4 \%$ BSA/PBS. Hybridoma supernatants were added to the wells then incubated for $30 \mathrm{~min}$. Plates were washed $3 \mathrm{x}$ with $0.2 \%$ Tween-20/PBS. Biotinylated CCL17 or CCL22 was added and allowed to incubate for $30 \mathrm{~min}$ at room temperature. After washing the plates, 3x streptavidin-HRP (Jackson Immunoresearch) was diluted 1:40,000 in 0.4\% BSA/PBS, then added to the wells and incubated for $30 \mathrm{~min}$ at room temperature. Plates were washed $3 x$ with $0.2 \%$ Tween-20/ PBS before addition of SigmaFAST OPD substrate (SigmaAldrich, St. Louis, MO). The plates were incubated at room temperature for $15 \mathrm{~min}$ and the reaction was stopped by addition of $4 \mathrm{~N} \mathrm{H}_{2} \mathrm{SO}_{4}$. Results of the colorimetric reaction were read using Powerwave HT340 at $490 \mathrm{~nm}$ and Gen5 software (both from BioTek, Winooski, VT).

\section{Calcium flux assays}

Calcium mobilization assay was performed using hybridoma antibodies purified from culture supernatant using Dynabeads Protein G (Invitrogen, Grand Island, NY) and CCRF-CEM cell-human T lymphoblastic cell line. Briefly, cells were cultured in RPMI with GlutaMAX, 10\% FBS, $10 \mathrm{mM}$ Hepes, $1 \mathrm{mM}$ sodium pyruvate, $4500 \mathrm{mg} / \mathrm{L}$ glucose, and $1500 \mathrm{mg} / \mathrm{mL}$ sodium bicarbonate at $37^{\circ} \mathrm{C}$ incubator with $5 \% \mathrm{CO}_{2}$. The cells were harvested by centrifugation, resuspended at $1.6 \times 10^{6}$ cells $/ \mathrm{mL}$, and seeded in 384-well poly-D-lysine coated black view assay plate (Greiner BioOne, Monroe, NC) in the presence of Fluo- 8 NW dye-loading buffer (ABD Bioquest, Sunnyvale, CA); the buffer consists of $10 \mu \mathrm{L}$ Fluo-8 NW, $1 \mathrm{~mL}$ 10x Pluronic F127 Plus, and $19 \mathrm{~mL}$ assay buffer with $0.1 \%$ BSA, which was allowed to incubate at $37^{\circ} \mathrm{C}$ with $5 \% \mathrm{CO}_{2}$ for $30 \mathrm{~min}$. Purified hybridoma $\alpha-$ CCL17 antibodies, MAB529 control antibodies, rat igG2a isotype control MAB006 (latter two antibodies from R\&D Systems), or assay buffer was pre-incubated with mCCL17 for $60 \mathrm{~min}$ at room temperature. Calcium mobilization was assessed using FDSS 6000 (Hamamatsu, Bridgewater, NJ) to measure the fluorescence intensity using $490 \mathrm{~nm}$ excitation and $525 \mathrm{~nm}$ emission.

FIG. 1. Effect of purified hybridoma-generated anti-CCL17 antibodies on mouse CCL17 bioactivity. Hybridoma-generated antibodies that were shown to bind CCL17 by ELISA were screened for inhibitors of CCL17 function using the calcium mobilization assay. (A-D) Purified hybridoma antibodies, control anti-mouse CCL17 antibody, and rat IgG2a isotype controls were pre-incubated in the presence or absence of $2 \mathrm{ng} / \mathrm{mL}$ mouse CCL17, then added to CCRF-CEM cells containing Fluo-8 dye-loading buffer. Calcium mobilization was determined by measuring the florescence intensity. Controls are shown to the left of each panel. Antagonist antibodies were defined as those that reduced florescent intensity to levels less than or equal to 3 standard deviations of the mean of the fluorescence intensity seen with mouse CCL17 alone. 


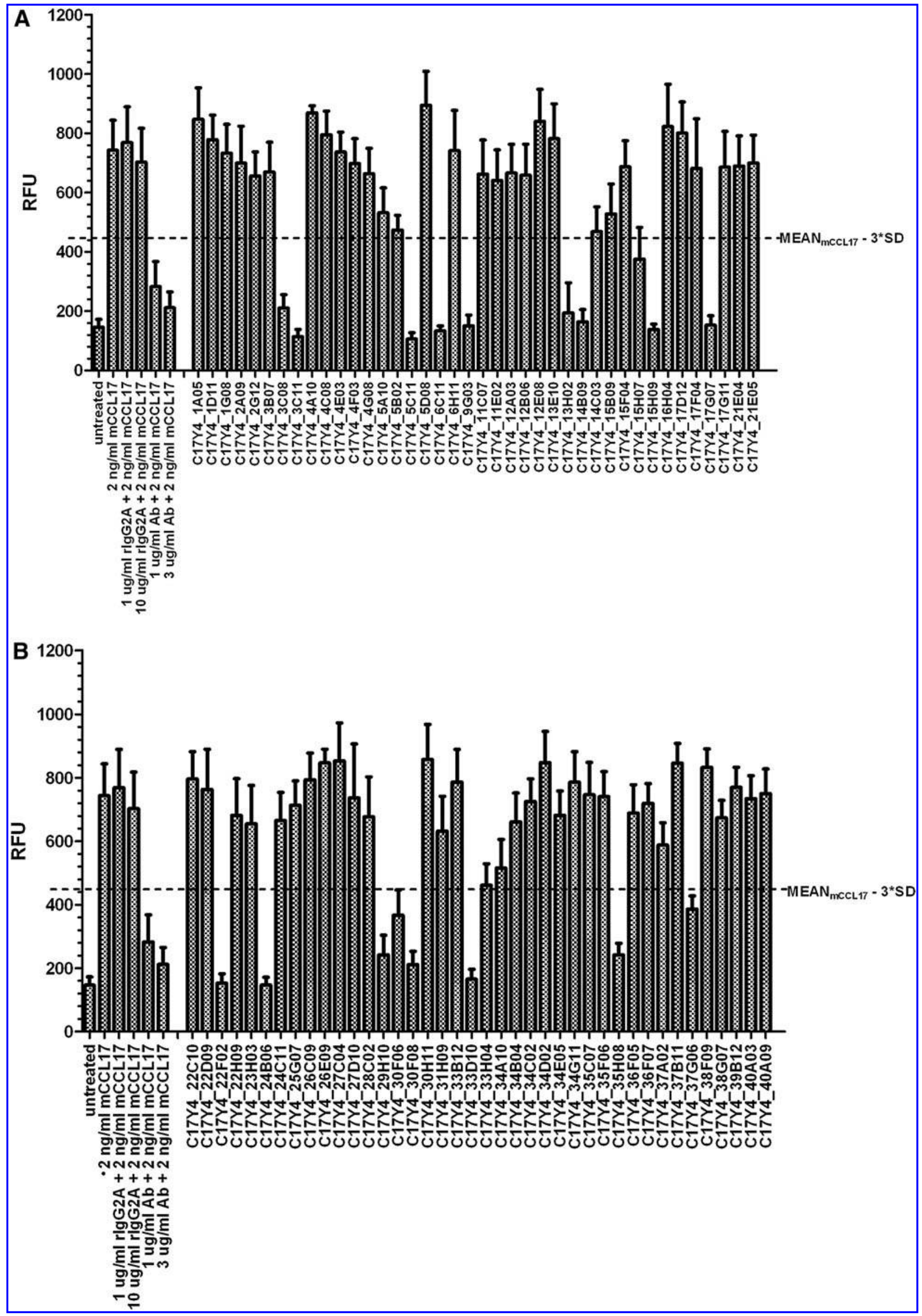




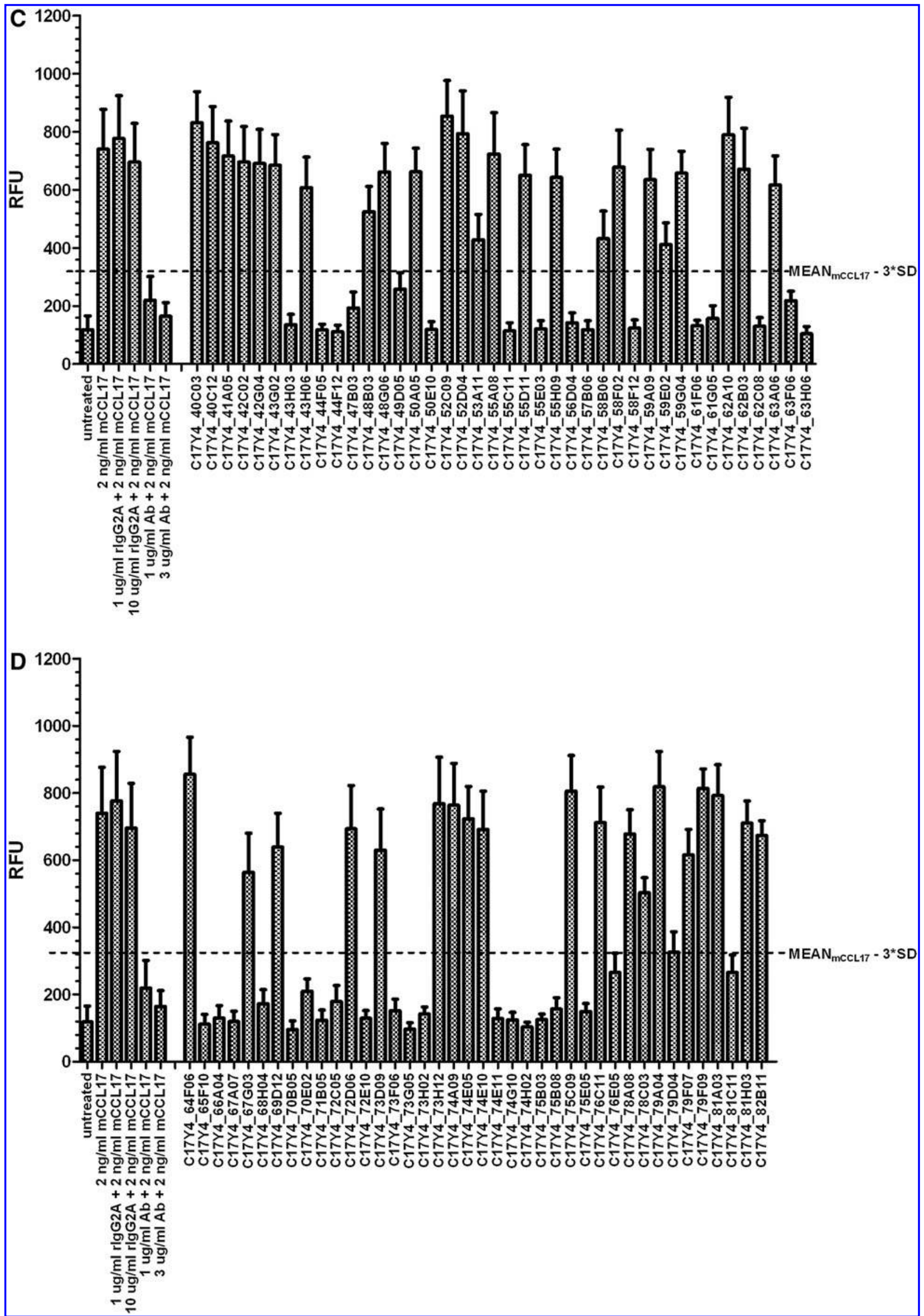

FIG. 1. Continued. 


\section{Antibody cloning and expression}

The $V_{H}$ and $V_{L}$ region genes were cloned from each of the rat hybridomas expressing $\alpha$-mouse CCL17 antibodies. The chimeric antibodies were expressed as mouse $\mathrm{IgG}_{1} / \kappa$ antibodies in HEK 293 F cells. Purification of the chimeric antibodies was performed using MabSelectSuRe (GE Healthcare Bio-Sciences) and AKTAxpress followed by elution using $0.1 \mathrm{M}$ sodium acetate ( $\mathrm{pH}$ 3.5) and subsequent dialysis into DPBS ( $\mathrm{pH}$ 7.2). Endotoxin was removed using ActiClean resin (Sterogene Bioseparations, Carlsbad, CA). Quality and purity were assessed by SDS-PAGE and SEC HPLC (TSKgel BioAssist G3SWXL, Tosoh Bioscience, King of Prussia, PA).

\section{Chemotaxis}

The neutralizing activity of the surrogate panel was assessed in a chemotaxis assay using EL4 cells, and compared to effects of isotype control MAbs CNTO5516 (rat-mouse IgG chimeric), MAB006 (rat IgG2a), and MAB529 (latter two MAbs from R\&D Systems). Chemotaxis was induced using mouse CCL17, and the migration of EL4 cells through a 5- $\mu \mathrm{m}$ filter was assessed using a 96-well chemotaxis plate (Neuro Probe, Gaithersburg, MD). Ligand and/or antibody were added to the lower chamber and the antibody concentrations ranged from 0.25 to $10 \mu \mathrm{g} / \mathrm{mL}$. EL4 cells were washed with PBS and suspended in RPMI containing $0.1 \%$ BSA at a density of $0.5 \times 10^{6}$ cells $/ \mathrm{mL}$, and $70 \mu \mathrm{L}$ of this cell suspension was added to the upper chambers. The chemotaxis plates were incubated for $60 \mathrm{~min}$ in a $5 \% \mathrm{CO}_{2}$-humidified incubator at $37^{\circ} \mathrm{C}$, and cells migrating across the membrane into the lower chamber were measured using the Cell Titer-Glo Luminescence Cell Viability Assay (Promega, Madison, WI).

\section{$\beta$-arrestin assay}

The $\beta$-arrestin recruitment assay was performed as described previously using human CCR4 expressing $\mathrm{CHO}$ cells and the PathHunter eXpress $\beta$-arrestin Human and Ortholog GPCR assay (DiscoveRx, Fremont, CA), according to the manufacturer's recommendations. Mouse CCL17 was preincubated in the presence or absence of $\alpha$-CCL17 chimeric antibody, $\alpha$-CCL17 control antibody MAB529 (R\&D Systems), or isotype control MAB006 (all from R\&D Systems) for 20$30 \mathrm{~min}$ at $37^{\circ} \mathrm{C}$ with $5 \% \mathrm{CO}_{2}$ before the addition to cells. Following addition to the cells, the assay was allowed to proceed for $90 \mathrm{~min}$. Chemiluminescent detection substrates were added and incubated at room temperature for $60 \mathrm{~min}$. Luminescence readings were taken on the Victor ${ }^{3} \mathrm{~V}$ Wallac1420 Multilabel plate reader (Perkin Elmer, Shelton, CT) and analyzed on GraphPad Prism software (San Diego, CA). For dose curves, concentration started at $1 \mu \mathrm{M}$ with a 1:2 dilution series. For antibody inhibition studies, mouse CCL17 was used at a constant concentration of $30 \mathrm{nM}$.

\section{Results}

\section{Generation and functional characterization of rat anti-mouse surrogate antibodies}

Hybridomas were generated by fusion of splenocytes prepared from rats immunized with recombinant CCL17. A panel of 160 antibodies was identified by screening for CCL17 binding using a capture ELISA and these hybridomas were scaled up for further evaluation in functional assays. Confirmation of CCL17 specificity following scale up was done by ELISA and subsequent cross-screening on mouse CCL22, which identified only a single clone as having detectable cross-reactivity for CCL22. All clones were further tested for ability to inhibit CCL17 function.

The panel of 160 hybridomas was screened for antibodies that inhibit CCL17 function in a high throughput calcium flux assay using human CCRF-CEM cells, which mobilize calcium in response to stimulation with mouse CCL17. ${ }^{(17)}$ Small-scale purification was performed on each antibody in the panel, and the purified antibodies were incubated with recombinant mouse CCL17 prior to addition to CCRF-CEM cells. Those antibodies that blocked release of calcium to levels $\leq 3$ standard deviations of the mean as defined by treatment with CCL17 either alone or in the presence of control antibodies were considered neutralizing (Fig. 1). Because these samples were from the primary hybridoma cultures, there was insufficient material to perform the assay using normalized concentrations for all samples so the possibility exists that some potentially neutralizing clones would be missed due to lower antibody concentration. Conversely, there may also be clones having very high antibody concentrations in the culture supernatant that would be tagged as neutralizing when in fact the effect is an artifact of non-specific binding. However, using this assay, we were able to identify 54 clones capable of neutralizing CCL17 functional activity.

\section{Chimeric anti-CCL17 antibodies act as antagonists for CCL17 signaling through CCR4 in dose-dependent manner}

Subsequent characterization of the antagonistic properties was conducted with chimeric antibodies in three functional assays: calcium mobilization, chemotaxis, and $\beta$-arrestin recruitment. To accommodate downstream in vivo studies, the rat $\mathrm{V}_{\mathrm{H}}$ and $\mathrm{V}_{\mathrm{L}}$ regions were molecularly cloned and expressed as chimeric mouse $\operatorname{IgG}_{1}$ antibodies. As a confirmatory assay to demonstrate that these antibodies could inhibit CCL17 function, they were tested for the ability to block chemotaxis in response to CCL17. ${ }^{(3,18)}$ As shown in Figure 2, antibodies that were initially identified as inhibitory in the calcium mobilization screen as hybridoma supernatants also inhibited CCL17mediated chemotaxis of EL4 cells when expressed as chimeric antibodies. Neither CCL17 specificity nor antagonistic activity was lost upon conversion of the hybridoma antibodies from fully rat antibodies to rat-mouse chimeric antibodies.

To confirm that the antibodies block CCL17 function through CCR4, we next investigated whether any of the antibodies would also inhibit $\beta$-arrestin recruitment. Chemotaxis mediated by CCL17 occurs through engagement of the $\mathrm{G}_{\mathrm{i}}$ coupled GPCR CCR4, which activates subsequent GPCR signaling pathways, including recruitment of $\beta$-arrestin. $(3,19,20)$ Since it had previously been determined that human cells are responsive to murine CCL17 in the calcium flux assay, we reasoned that a human cell line-based reporter system could be employed. ${ }^{(17)}$ The antibodies were compared for their ability to inhibit CCL17 function using a commercially available cell line engineered to become luminescent when signaling through CCR4 induces recruitment of $\beta$-arrestin. Dose-response curves were performed for each of the antibodies in the panel, thus allowing us to compare their 


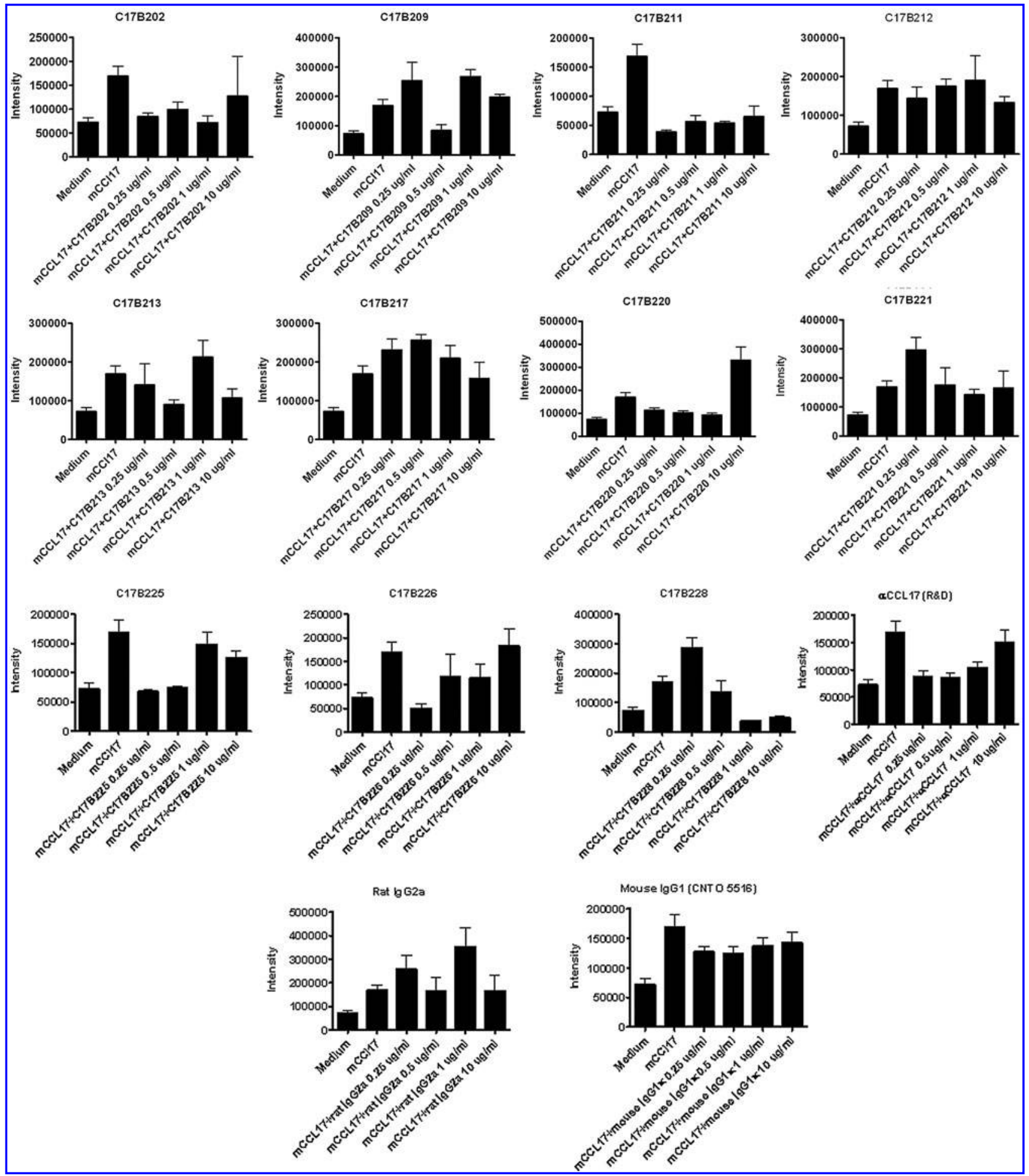

FIG. 2. Chimeric anti-CCL17 antibodies that inhibit calcium mobilization also inhibit CCL17-mediated chemotaxis. EL4 cells were incubated with $2 \mathrm{ng} / \mathrm{mL}$ mouse CCL17 in the presence and absence of each of the chimeric antibodies or control antibodies. Data for control antibodies are as follows: positive control antibody (R\&D MAb529) and corresponding isotype control (Rat IgG2 2 ,CNTO5516). Samples were run in triplicate and data are shown as the average \pm SD for each condition. 
inhibitory activity (Fig. 3). The antibodies tested inhibited $\beta$ arrestin recruitment in response to CCL17, indicating that we are specifically blocking signaling through CCR4 in this system. Of note, B220 appears to have a non-sigmoidal doseresponse curve in this assay. However, we have not reached a plateau at the lower concentrations of antibody in this experiment so the resulting dose-response curve is incomplete. Expanding the range of antibody concentrations tested would most likely yield a sigmoidal curve in this assay.

That the anti-CCL17 antibodies differ in antagonistic activity became evident from the dose-response data generated in the $\beta$-arrestin recruitment assay. Although the antibodies were originally identified as antagonistic by screening in a calcium mobilization assay, this was performed using hybridoma supernatants that were not concentration-normalized. In this setting, the chances for discerning differences between the antibodies are minimal at best. To determine whether there was any correlation between antagonistic potential in the calcium mobilization assay and $\beta$-arrestin assay, calcium mobilization was repeated using dose response curves of the antibodies. In contrast to the $\beta$-arrestin assay, differences in antagonistic activity among the antibodies were not evident with respect to calcium mobilization (Fig. 4). Most of the antibodies have overlapping dose response curves that fall into a relatively tight range with the exception of B226 and to a limited degree B225 (Fig. 4A). The calcium mobilization assay is appropriate for screening but does not provide the level of sensitivity required to differentiate the antibodies based on antagonistic activity.

Given that mouse CCL17 functions through human CCR4, we reasoned that generation of cross-species binding antibodies could be possible. However, because the overall identity of the proteins is $64 \%$, with $80 \%$ homology between human and mouse CCL17, any cross-reactive antibodies would most likely be less effective at blocking mouse CCL17 function. Out of the panel of 11 chimeric antibodies, a total of five were identified as mouse-human cross-reactive by ELISA (data not shown). Comparison of antagonistic effects on mouse CCL17-mediated function between those antibodies specific for mouse CCL17 and those that recognize both mouse and human CCL17 in recruitment of $\beta$-arrestin show that the mouse-human cross-reactive antibodies appear to have $\mathrm{IC}_{50}$ within a relatively tight range (Fig. 3B). The same is true for four of the six antibodies specific for mouse CCL17 (Fig. 3A); however, dose response curves for B225 and B220 are both shifted to the left of the majority. Similar results are seen in the comparison of calcium mobilization data in that, with the exception of B226 and possibly B225, the dose response curves largely overlap (Fig. 4). Taken together, these data suggest that there is no functional advantage for those antibodies that bound both proteins; all the antibodies within the panel could be demonstrated to inhibit mouse CCL17 function with comparable activity.

\section{Discussion}

The goal of this experiment was to generate tools that would inhibit CCL17 function mediated by CCR4 interaction, thus enabling future studies to understand CCL17-specific effects on CCR4 without impacting CCL22. Much information regarding the receptor CCR4 in disease conditions has been facilitated by availability of CCR4-knockout mice, but these results are ligand-independent in that neither CCL17 nor CCL22 are known to interact with any other receptors. ${ }^{(21)}$ Teasing out any differential effects associated with binding of the individual ligands to CCR4 requires CCL17- and CCL22specific antibodies that lack cross-reactivity to both chemokines. This panel of antibodies specific for CCL17 was generated by producing hybridomas from immunized rats followed by conversion of the antagonistic antibodies to mouse-rat chimeras. These antibodies inhibit CCL17 function even though there is a high degree of similarity between the rat and mouse proteins; mouse and rat CCL17 share 91\% homology and $83 \%$ identity at the amino acid level differing by only six amino acids. These chimeric antibodies have been demonstrated to specifically neutralize CCL17 in vitro using three different functional assays. The antagonistic nature of the surrogate antibodies in vitro means they can be utilized to elucidate the relative contributions of CCL17 and CCL22 in mouse models of disease.
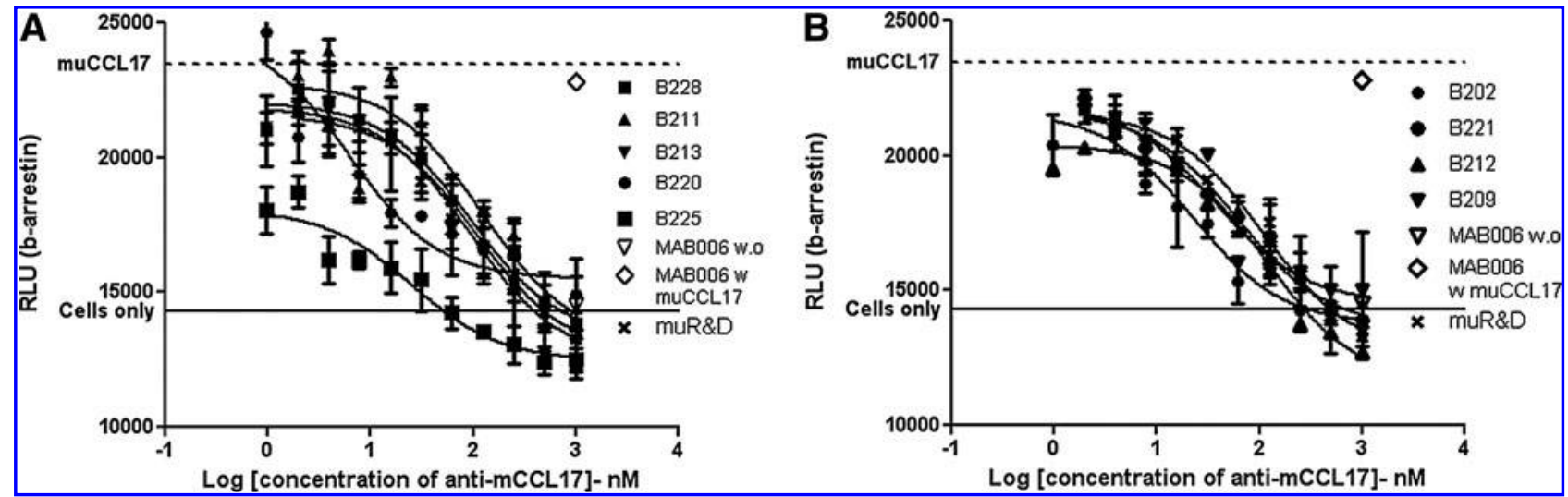

FIG. 3. Inhibition of CCL17 function is the result of interference with CCR4 signaling. Dose-response curves were run using purified chimeric antibodies to test for the ability to inhibit $\beta$-arrestin recruitment induced by CCR4 signaling. Controls include anti-CCL17 MAB529 (x) and isotype control MAB006 $\nabla$ ) run as positive and negative controls, respectively. Note that control antibodies were assayed only at the highest antibody concentration, $1 \mu \mathrm{M}$, and are illustrated as a single point. Starting antibody concentration for dose curves was $1 \mu \mathrm{M}$ with 1:2 serial dilutions. (A) Antibodies that bind mouse CCL17 only. (B) Antibodies that bind both mouse and human CCL17. Data shown are representative of three experiments. 


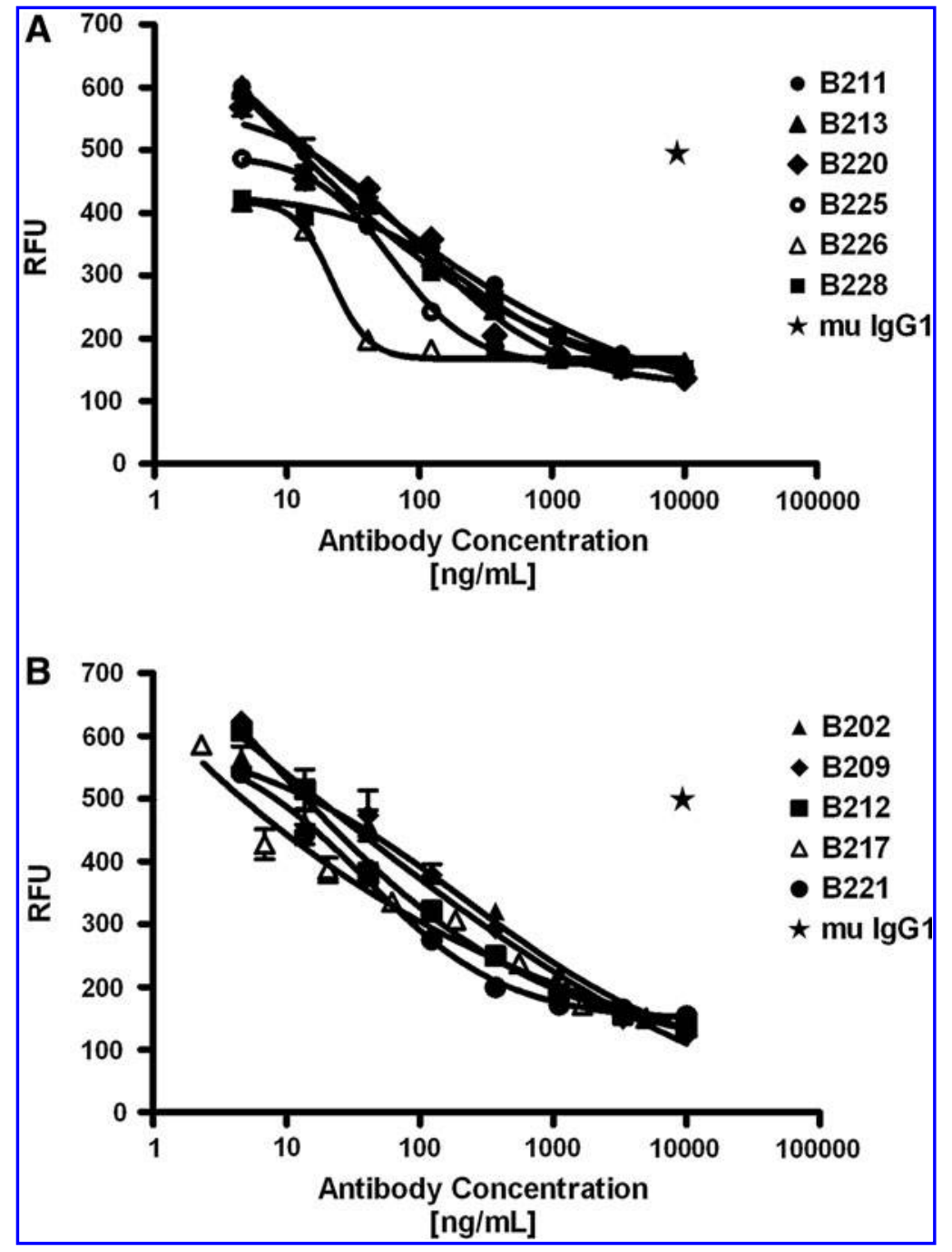

FIG. 4. Calcium mobilization in response to CCL17 signaling is inhibited by chimeric antibodies in a dose-dependent manner. CCRF-CEM cells were treated in quadruplicate with mouse CCL17 at $2 \mathrm{ng} / \mathrm{mL}$ in the presence of each antibody starting at $10 \mu \mathrm{g} / \mathrm{mL}$. Control antibody (asterisk) was run only at the highest concentration of $10 \mu \mathrm{g} / \mathrm{mL}$. Data shown are representative of two experiments. (A) Antibodies that bind mouse CCL17 only. (B) Antibodies that bind both mouse and human CCL17.

Even though both chemokines function through CCR4, homology between CCL17 and CCL22 is not that high; however, the most conserved regions in the amino acid sequence are proposed to reside within the predicted receptor binding site. ${ }^{(1,22)}$ For this reason, cross-reactivity with CCL22 was of particular concern as the screening strategy was established to identify antibodies that could neutralize CCL17 function, which in turn would likely involve CCR4 interaction. To minimize the possibility of carrying an antibody forward that binds both proteins, the entire panel of CCL17specific antibodies was cross-screened on CCL22, leading to the identification of one clone. The binding profile of the MAbs in this panel demonstrates CCL17 selectivity, and the lack of detectable CCL22 binding suggests that there would be no interference with CCL22 function. However, additional analysis of these antibodies using in vitro assays that depend on CCL22 function would need to be done to confirm that these two chemokines function independently of each other. If neutralization of CCL17 function is achieved by blocking interaction with CCR4, this result might have been interpreted as few, if any, neutralizing antibodies were contained in the panel. However, we found approximately one-third of the antibodies tested to be CCL17 neutralizing antibodies (Fig. 5). It is possible that all of the CCL17 binding antibodies have some neutralizing capability but the activity is below the detection sensitivity of the screening assay, for example, if they bind with low affinity. This result does not completely rule out the possibility that at least some of the antibodies inhibit CCL17 function by steric hindrance, thus indirectly interfering with CCR4 interaction rather than blocking the actual CCR4 binding site on the ligand.

Out of the panel of neutralizing antibodies, only a single antibody could be confirmed to bind to CCL22 even though these two chemokines function through the same receptor and have been reported to compete with each other for CCR4 binding. ${ }^{(1)}$ One explanation for this may be that CCL22 is produced by activated B cells and dendritic cells (DC) in order to attract and retain $\mathrm{T}$ cell help by local immobilization. ${ }^{(17,23)}$ CCL17 is also produced by activated B cells and DCs; however, this chemokine is produced by many different cell types, 


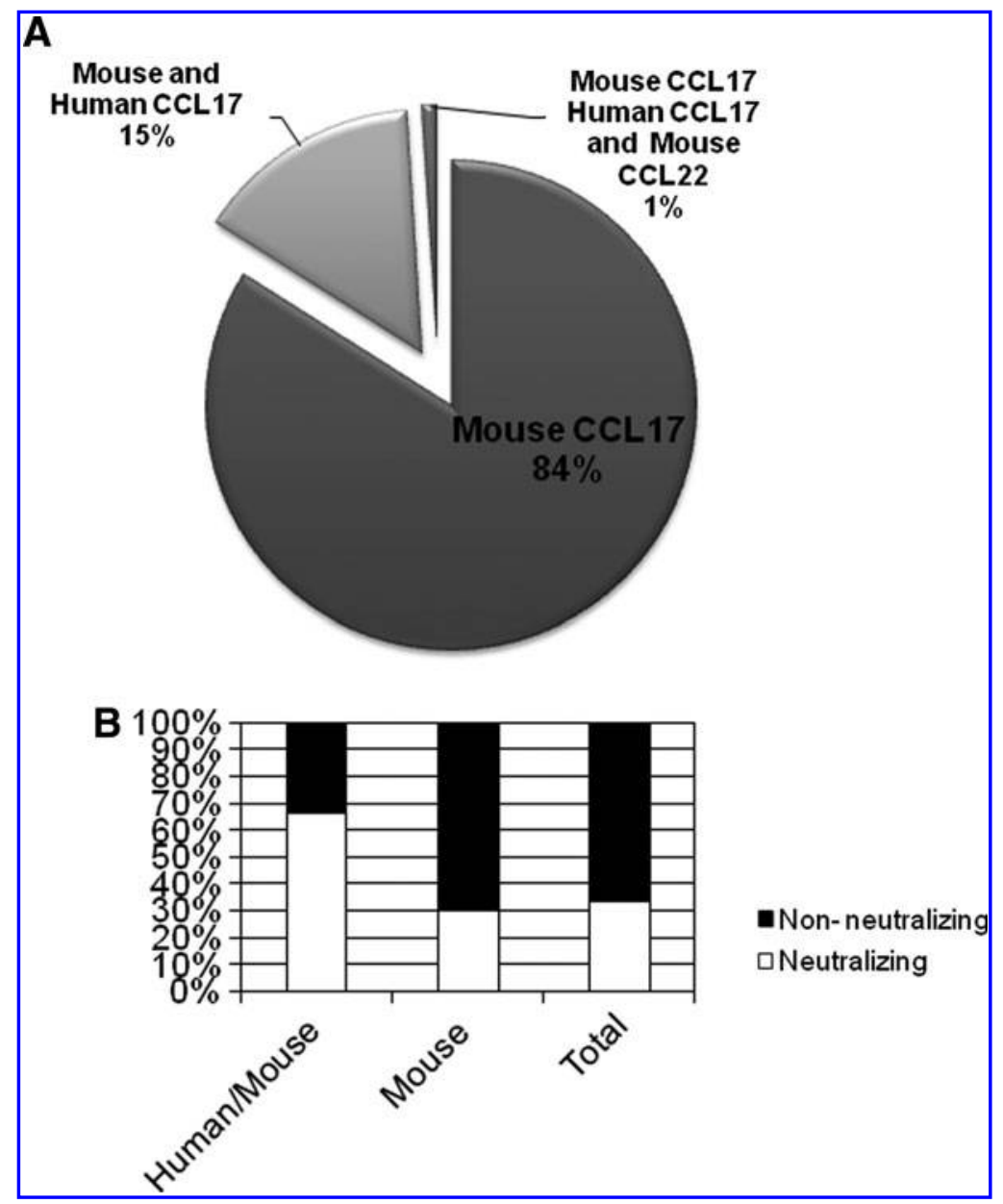

FIG. 5. Frequency and specificity overview of anti-CCL17 hybridomas. (A) Frequency of mouse CCL17-specific hybridomas that bind human CCL17 and mouse CCL22 based on ELISA data from primary screen of hybridomas. All hybridomas were selected based on mouse CCL17 binding; frequency is expressed as a percentage of all mouse CCL17-specific hybridomas. (B) Distribution of antagonistic antibodies based on binding specificity. Antagonistic antibodies were identified from a panel of hybridomas specific for mouse CCL17 using calcium mobilization high throughput screen. Data are presented as the percentage of antibodies that are antagonistic according to binding specificities. The total number of hybridomas for each binding profile represents $100 \%$ of that subgroup with the relative frequency of neutralizing and non-neutralizing hybridomas plotted for each.

including both immune and non-immune cells. For example, macrophages, fibroblasts, keratinocytes, epithelial cells, airway smooth muscle cells, and Langerhans cells produce CCL17 while CCL22 is produced only by immune cells. ${ }^{(11,24-26)}$ Inequalities in the ability of the two chemokines to mediate cell adhesion in vitro have been reported in that CCL22 tends to improve cell-cell binding. ${ }^{(4)}$ Perhaps the differential expression pattern and the superior ability of CCL22 to mediate lymphocyte adhesion result in localized retention of immune cells, which could promote an immune response through cell-cell interactions and co-stimulation. Blocking CCL22 function in this case by inducing an anti-CCL22 antibody response could potentially disrupt the localized cellular interactions and inhibit co-stimulation, resulting in an overall down-regulation of the response and providing a natural screening system to eliminate CCL22 specific antibody production.

Cross-screening of the antibodies selected for mouse CCL17 binding revealed that a subset of antibodies bind human CCL17 as well as mouse. Mouse CCL17 is also capable of signaling through human CCR4 even though there is only $66 \%$ identify and $83 \%$ homology between mouse and human
CCL17. ${ }^{(17)}$ This makes it likely that the amino acids conserved between the two species are involved in CCR4 binding. If so, then we could expect that antibodies that neutralize mouse CCL17 may bind human CCL17 as well. However, when the panel of CCL17 binding antibodies was screened for reactivity to human CCL17, most of the antibodies (84\%) were found to bind only to mouse CCL17, 30\% of which were neutralizing (Fig. 5). The subset of human-mouse cross-reactive antibodies comprises only $15 \%$ of the panel, yet almost $70 \%$ of the antibodies in this subset are neutralizing, which suggests that the epitope(s) recognized by these cross-reactive antibodies is important for CCL17 function (Fig. 5).

In summary, antibodies that inhibit mouse CCL17 function but do not bind CCL22 can be generated by immunizing rats in spite of the high degree of homology with rat CCL17. Even though mouse CCL17 can signal through human CCR4, only a fraction of the antibodies described herein bind CCL17 from both species. These antibodies have been converted from fully rat antibodies to rat-mouse chimeric antibodies expressed as mouse IgG1, which makes them ideal for in vivo studies using mouse models. 


\section{Author Disclosure Statement}

Authors A. Coelho and C.M. Hogaboam received funding for this study from Janssen, Research \& Development.

\section{References}

1. Imai T, Chantry D, Raport CJ, Wood CL, Nishimura M, Godiska R, Yoshie O, and Gray PW: Macrophage-derived chemokine is a functional ligand for the CC chemokine receptor 4. J Biol Chem 1998;273:1764-1768.

2. Allen SJ, Crown SE, and Handel TM: Chemokine: receptor structure, interactions, and antagonism. Annu Rev Immunol 2007;25:787-820.

3. Imai $T$, Baba $M$, Nishimura $M$, Kakizaki $M$, Takagi $S$, and Yoshie O: The T cell-directed CC chemokine TARC is a highly specific biological ligand for CC chemokine receptor 4. J Biol Chem 1997;272:15036-15042.

4. D'Ambrosio D, Albanesi C, Lang R, Girolomoni G, Sinigaglia $\mathrm{F}$, and Laudanna C: Quantitative differences in chemokine receptor engagement generate diversity in integrin-dependent lymphocyte adhesion. J Immunol 2002;169:2303-2312.

5. Mariani M, Lang R, Binda E, Panina-Bordignon $\mathrm{P}$, and D'Ambrosio D: Dominance of CCL22 over CCL17 in induction of chemokine receptor CCR4 desensitization and internalization on human Th2 cells. Eur J Immunol 2004;34: 231-240.

6. Baatar D, Olkhanud P, Newton D, Sumitomo K, and Biragyn A: CCR4-expressing $\mathrm{T}$ cell tumors can be specifically controlled via delivery of toxins to chemokine receptors. I Immunol 2007;179:1996-2004.

7. Matsukawa A, Hogaboam CM, Lukacs NW, Lincoln PM, Evanoff HL, and Kunkel SL: Pivotal role of the CC chemokine, macrophage-derived chemokine, in the innate immune response. J Immunol 2000;164:5362-5368.

8. Carpenter $\mathrm{KJ}$, and Hogaboam CM: Immunosuppressive effects of CCL17 on pulmonary antifungal responses during pulmonary invasive aspergillosis. Infect Immun 2005;73: 7198-7207.

9. Weber C, Meiler S, Doring Y, Koch M, Drechsler M, Megens RT, Rowinska Z, Bidzhekov K, Fecher C, Ribechini E, van Zandvoort MA, Binder CJ, Jelinek I, Hristov M, Boon L, Jung S, Korn T, Lutz MB, Forster I, Zenke M, Hieronymus T, Junt $\mathrm{T}$, and Zernecke A: CCL17-expressing dendritic cells drive atherosclerosis by restraining regulatory $\mathrm{T}$ cell homeostasis in mice. J Clin Invest 2011;121:2898-2910.

10. Heiseke AF, Faul AC, Lehr HA, Forster I, Schmid RM, Krug $\mathrm{AB}$, and Reindl W: CCL17 promotes intestinal inflammation in mice and counteracts regulatory $\mathrm{T}$ cell-mediated protection from colitis. Gastroenterology 2012;142:335-345.

11. Alferink J, Lieberam I, Reindl W, Behrens A, Weiss S, Huser N, Gerauer K, Ross R, Reske-Kunz AB, Ahmad-Nejad P, Wagner $\mathrm{H}$, and Forster I: Compartmentalized production of CCL17 in vivo: strong inducibility in peripheral dendritic cells contrasts selective absence from the spleen. I Exp Med 2003;197:585-599.

12. Conroy DM, Jopling LA, Lloyd CM, Hodge MR, Andrew DP, Williams TJ, Pease JE, and Sabroe I: CCR4 blockade does not inhibit allergic airways inflammation. I Leukoc Biol 2003;74:558-563.

13. Perros F, Hoogsteden HC, Coyle AJ, Lambrecht BN, and Hammad H: Blockade of CCR4 in a humanized model of asthma reveals a critical role for DC-derived CCL17 and CCL22 in attracting Th2 cells and inducing airway inflammation. Allergy 2009;64:995-1002.
14. Abi-Younes S, Si-Tahar M, and Luster AD: The CC chemokines MDC and TARC induce platelet activation via CCR4. Thromb Res 2001;101:279-289.

15. Nakagami Y, Kawashima K, Yonekubo K, Etori M, Jojima T, Miyazaki S, Sawamura R, Hirahara K, Nara F, and Yamashita M: Novel CC chemokine receptor 4 antagonist RS-1154 inhibits ovalbumin-induced ear swelling in mice. Eur J Pharmacol 2009;624:38-44.

16. de St Groth SF, and Scheidegger D: Production of monoclonal antibodies: strategy and tactics. J Immunol Methods 1980;35:1-21.

17. Schaniel C, Sallusto F, Ruedl C, Sideras P, Melchers F, and Rolink AG: Three chemokines with potential functions in $\mathrm{T}$ lymphocyte-independent and -dependent B lymphocyte stimulation. Eur J Immunol 1999;9:934-947.

18. Imai $T$, Nagira $M$, Takagi $S$, Kakizaki M, Nishimura $M$, Wang J, Gray PW, Matsushima K, and Yoshie O: Selective recruitment of CCR4-bearing Th2 cells toward antigenpresenting cells by the CC chemokines thymus and activationregulated chemokine and macrophage-derived chemokine. Intl Immunol 1999;11:81-88.

19. Cronshaw D: Activation of phosphoinositide 3-kinases by the CCR4 ligand macrophage-derived chemokine is a dispensable signal for $\mathrm{T}$ lymphocyte chemotaxis. J Immunol 2004;172.

20. Moroi Y, Yu B, Urabe K, Koga T, Nakahara T, Dainichi T, Uchi $\mathrm{H}$, and Furue M: Effects of MAPK inhibitors on CCR4-mediated chemotaxis against thymus and activation-regulated chemokine (TARC/CCL17). J Dermatol Sci 2004;36:186-188.

21. Schuh JM, Power CA, Proudfoot AE, Kunkel SL, Lukacs NW, and Hogaboam CM: Airway hyperresponsiveness, but not airway remodeling, is attenuated during chronic pulmonary allergic responses to Aspergillus in CCR4-/- mice. FASEB J 2002;16:1313-1315.

22. Asojo OA, Boulegue C, Hoover DM, Lu W, and Lubkowski J: Structures of thymus and activation-regulated chemokine (TARC). Acta Crystallogr D Biol Crystallogr 2003;59:11651173.

23. Wu M-T, Fang $\mathrm{H}$, and Hwant ST: Cutting edge: CCR4 mediates antigen-primed $\mathrm{T}$ cell binding to activated dendritic cells. J Immunol 2001;167:4791-4795.

24. Imai T, Yoshida T, Baba M, Nishimura M, Kakizaki M, and Yoshie O: Molecular cloning of a novel T cell-directed CC chemokine expressed in thymus by signal sequence trap using Epstein-Barr virus vector. J Biol Chem 1996;271:21514-21521.

25. Saeki $\mathrm{H}$, and Tamaki $\mathrm{K}$ : Thymus and activation regulated chemokine (TARC)/CCL17 and skin diseases. J Dermatol Sci 2006;43:75-84.

26. Berin MC, Eckmann L, Broide DH, and Kagnoff MF: Regulated production of the $\mathrm{T}$ helper 2-type T-cell chemoattractant TARC by human bronchial epithelial cells in vitro and in human lung xenografts. Am J Respir Cell Mol Biol 2001;24:382-389.

Address correspondence to: Dr. Sandra Santulli-Marotto Janssen Research \& Development 145 King of Prussia Road Radnor, PA 19087

E-mail: ssantull@its.jnj.com

Received: December 4, 2012 Accepted: February 5, 2013 


\section{This article has been cited by:}

1. Dayana Abboud, Julien Hanson. 2016. Chemokine neutralization as an innovative therapeutic strategy for atopic dermatitis. Drug Discovery Today . [CrossRef]

2. Raymond H. de Wit, Sabrina M. de Munnik, Rob Leurs, Henry F. Vischer, Martine J. SmitMolecular Pharmacology of Chemokine Receptors 457-515. [CrossRef]

3. Santulli-Marotto Sandra, Wheeler John, Lacy Eilyn R., Boakye Ken, Luongo Jennifer, Wu Sheng-Jiun, Ryan Mary. 2015. CCL22-specific Antibodies Reveal That Engagement of Two Distinct Binding Domains on CCL22 Is Required for CCR4mediated Function. Monoclonal Antibodies in Immunodiagnosis and Immunotherapy 34:6, 373-380. [Abstract] [Full Text HTML] [Full Text PDF] [Full Text PDF with Links]

4. B. C. Martel, L. Blom, B. Dyring-Andersen, L. Skov, K. Thestrup-Pedersen, S. Skov, K. Skak, L. K. Poulsen. 2015. Human Atopic Dermatitis Skin-derived T Cells can Induce a Reaction in Mouse Keratinocytes in vivo. Scandinavian Journal of Immunology 82:2, 125-134. [CrossRef]

5. J. W. Kehoe, B. Whitaker, D. Bethea, E. R. Lacy, K. Boakye, S. Santulli-Marotto, M. H. Ryan, Y. Feng, J. C. Wheeler. 2014. Isolation and optimization for affinity and biophysical characteristics of anti-CCL17 antibodies from the VH1-69 germline gene. Protein Engineering Design and Selection 27:6, 199-206. [CrossRef] 